\title{
Hydrodynamic Studies on a Trickle Bed Reactor for Foaming Liquids
}

\author{
Renu Gupta and Ajay Bansal *
}

\author{
Department of Chemical Engineering, Dr B R Ambedkar National Institute of Technology, \\ Jalandhar-144011, Punjab, INDIA
}

Received: 16 January 2010; Revised: 10 February 2010; Accepted: 21 February 2010

\begin{abstract}
Hydrodynamic studies of trickle bed reactors (TBRs) are essential for the design and prediction of their performance. The hydrodynamic characteristics involving pressure drop and dynamic liquid saturation are greatly affected by the physical properties of the liquids. In the present study experiments have been carried out in a concurrent downflow air - liquid trickle bed reactor to investigate the dynamic liquid saturation and pressure drop for the water (non-foaming) and 3\% polyethylene glycol and 4\% polyethylene glycol foaming liquids in the gas continuous regime (GCF) and foaming pulsing regime (FP). In the GCF regime the dynamic liquid saturation was found to increase with increase in liquid flow rate for non-foaming and foaming liquids. While for $3 \%$ and $4 \%$ polyethylene glycol solutions the severe foaming was observed in the high interaction regime and the regime is referred to as foaming pulsing (FP) regime. The decrease in dynamic liquid saturation followed by a sharp rise in the pressure drop was observed during transition from gas GCF to FP regime. However in the FP regime, a dip in the dynamic liquid saturation was observed. The pressure drop for foaming liquids is observed to be manifolds higher compared to non-foaming liquid in the GCF regime. C 2010 BCREC UNDIP. All rights reserved.
\end{abstract}

Keywords: Trickle bed reactor, Dynamic liquid saturation, Pressure drop, Foaming liquids

\section{Introduction}

Trickle bed reactors (TBRs) with downward flow of gas and liquid have wide applications in the petroleum and petrochemical industries. Many petroleum products like naphtha, diesel fuels, kerosene and crude lubricating oils have a tendency to produce foam during processing. Studies about the hydrodynamics of trickle beds implying systems with a propensity to foam still belong to the category of orphan research topics in comparison to the overwhelming body of literature devoted to non-foaming trickle-bed systems [1].
Depending on the gas-liquid interactions, four flow regimes have been observed for non foaming liquids [2-3]. These regimes are: trickle flow regime or gas continuous regime (GCF), pulse flow regime $(\mathrm{PF})$, spray flow regime and bubble flow regime. The above mentioned flow regimes can broadly be categorised as a low interaction regime, including the trickling flow only, and a high interaction regime, comprising all the other flow regimes for both foaming and non-foaming systems [4]. Charpentier and Favier [2]; Bartelmus and Janecki [5] introduced the separate flow maps for foaming

* Corresponding Author

E-mail: drajaybansal@gmail.com (A. Bansal); bansala@nitj.ac.in (A. Bansal)

Tel: +91-181-2690301; Fax: +91-181-2690320 
and non-foaming systems. The foam formation is very likely connected with the physicochemical conditions of the interfacial surface. Foaming fluids behave differently than the non-forming fluids due to formation of foam in the high interaction regime.

Weekman and Myers [6] observed a large increase in pressure drop in the bed for foaming liquids. Wild et al. [7] observed the skyrocketing amplitudes of the pressure fluctuations for the foaming liquids when the flow pattern shifted from GCF to foaming pulsing FP regime. Twophase pressure drops that are reported to be higher may be due to foaming which characterizes enhanced interactions between gas and liquid phases.

Bartelmus and Janecki [8] observed that dynamic liquid saturation decreases during transition from GCF to FP regime due to appearance of foam for the foaming liquids. However in the FP regime the dynamic liquid saturation is reported to be almost independent of liquid flow rate. But with increase in gas flow rate the dynamic liquid saturation decreases in the FP regime. So far, a limited number of experimental studies on GCF and FP regime for foaming liquids have been available [1-10]. These authors reported that the values of dynamic liquid saturation for foaming systems are much lower than those prevailing with non-foaming systems of close physicochemical properties under identical flow rates of both phases. Mirroring dynamic liquid saturation trends, higher twophase pressure drops are reported to occur due to foaming which characterizes enhanced interactions between gas and liquid phases. Aydin and Larachi [10] have studied the effect of temperature on the dynamic liquid saturation. But none of the available studies have reported the effect of liquid flow rate on the dynamic liquid saturation in the FP regime. In the FP regime with further increase in liquid or gas flow rates the foaming intensity will increase due to high interactions of the phases which will further affect the dynamic liquid saturation and pressure drop. Liquid holdup or dynamic liquid saturation and pressure drop in the bed are the two key hydrodynamic parameters whose knowledge is necessary while designing and scaling up of the reactor. They are inseparable and appear together in the momentum balance equations of both fluids [8]. Pressure drop and dynamic liquid saturation are the important parameters in the process design and performance of trickle bed reactors as they affect the energy requirements and hence the operating cost and sizing of the reactor [11-12]. The appearance of foam is widespread in the industrial processes like petroleum industry, food and pharmaceutical industry, so there is a need to conduct a comprehensive study of the hydrodynamics of such systems in the GCF and FP regime. It is pertinent to mention here that industrial TBRs are operated close to pulsing but in the trickle regime. This is done to achieve the high throughput but to still have the lower pressure drops so as to have lower operating costs. As such it is worth while to investigate the hydrodynamics of TBR related to pressure drop and dynamic liquid saturation for the foaming liquids in the GCF and FP regime. Also the transition from GCF to FP has been investigated for foaming liquids in the present study.

\section{Experimental set up}

Experiments were carried out on a $10 \mathrm{~cm}$ diameter glass column, packed with spherical glass beads of $7.12 \mathrm{~mm}$ to a height of $100 \mathrm{~cm}$. Schematics of experimental set up are shown in Figure 1. Entry for gas and liquid phases were provided at the top of the column. The packing in the column was supported on a stainless steel mesh. For even distribution of liquid, a distributor is provided at the top of the column with 17 holes. The liquid distributor was placed at a height of $0.25 \mathrm{~m}$ above the packed bed. The details of the distributor are shown in Fig. 1(b). Air coming from the compressor via air surge tank was first saturated with water in a saturator before introducing into the packed bed. This would avoid the effect of mass transfer between gas and liquid phase inside the column. Pressure taps were provided across the packed section to measure the pressure drop.

The gas and liquid flow rates were measured by mass flow meter and rotameter. The column was initially flooded with liquid alone to completely wet the packing. It was drained before the liquid was introduced into the column at the desired rate. The flow pattern across the glass column was visually observed. For each run the gas flow was kept constant and the liquid flow rate was gradually increased in steps. No foam was noticed in the column at low liquid flow rates. However at high liquid flow rates considerable foam was observed with aqueous PEG solution. The dynamic liquid saturation of the system was studied by draining method. The inlet and outlet valves of the system were closed simultaneously. The liquid in the column was collected for 30 minutes. The liquid mass velocity, at which 


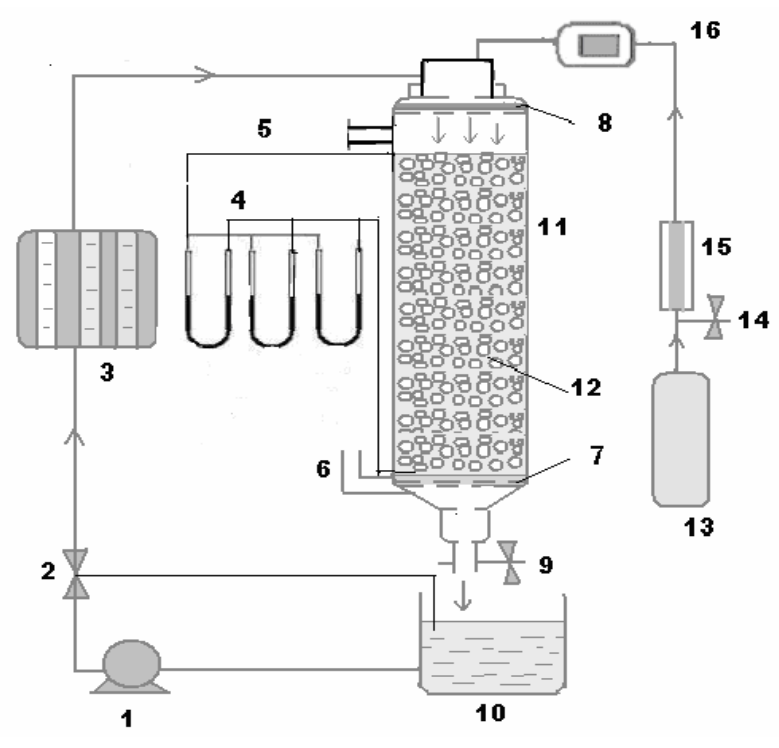

(a)

\begin{tabular}{|c|c|}
\hline 1. Pump & 2. Liquid control valve \\
\hline $\begin{array}{l}\text { 3. Rotameter flow control } \\
\text { valve }\end{array}$ & $\begin{array}{l}\text { 4. Manometers }\left(\mathrm{H}_{2} \mathrm{O} \text {, }\right. \\
\mathrm{Hg} \text { and } \mathrm{CCl}_{4} \\
\text { manometer })\end{array}$ \\
\hline 5. Packing inlet valve & 6. Air outlet port \\
\hline 7. Stainless steel mesh & 8. Liquid distributor \\
\hline $\begin{array}{l}\text { 9. Valve for liquid at } \\
\text { outlet }\end{array}$ & 10. Liquid storage tank \\
\hline 11. Glass column & 12. Packing material \\
\hline 13. Air compressor & 14. Air control valve \\
\hline 15. Mass flow meter & 16. Air saturator \\
\hline & $\begin{array}{l}\text { No of holes }=17 \\
\text { Hole diameter I.D }=1.5 \\
\text { mm. } \\
\text { Hole diameter O.D }=5 \\
\text { mm. } \\
\text { All dimensions are in } \\
\mathrm{mm} .\end{array}$ \\
\hline
\end{tabular}

(b)

Figure 1. Experimental set up. (a). Schematics of experimental set up. (b). Liquid distributor

transition was observed from GCF to FP regime i.e foam appeared in the column with a sharp rise in the pressure drop, was noted down. Corresponding to the visual observation of the onset of pulsing, the manometer fluid was found to show the fluctuations. In all systems, the onset of pulsing started at the bottom of the column and with increased gas flow rates of liquid at a constant gas rate, the point of pulse inception moved towards the column-top.

To observe the fluctuations corresponding to transition precisely, manometer with water was used. The transition was also confirmed from the $\Delta \mathrm{P} / \mathrm{Z}$ vs. L plots that showed a sharp rise in two

Table 1. Physical properties of liquids and air

\begin{tabular}{|c|c|c|c|}
\hline $\begin{array}{c}\text { System } \\
\text { At } \mathbf{2 0} \mathbf{~} \mathbf{C}\end{array}$ & $\begin{array}{c}\text { Density } \\
\mathbf{K g}^{\prime} / \mathbf{m}^{3}\end{array}$ & $\begin{array}{c}\text { Viscosity } \\
\text { Kg/m.s }\end{array}$ & $\begin{array}{c}\boldsymbol{\sigma} \\
\mathbf{N} / \mathbf{m}\end{array}$ \\
\hline Water & 998.29 & 0.001003 & 70 \\
\hline $3 \%$ PEG & 1012.4 & 0.001684 & 65 \\
\hline $4 \%$ PEG & 1014.4 & 0.00199 & 63 \\
\hline Air & 1.205 & 0.0000182 & - \\
\hline
\end{tabular}

phase pressure drop indicating the onset of pulsing. Physical properties of liquids used in the present study are listed in Table 1.

\section{Results and Discussion}

\subsection{Pressure Drop}

Figures 2 and 3 show the pressure drop for $3 \%$ and $4 \%$ PEG in the column as a function of liquid flow rate at various gas flow rates. It has been observed that the pressure drop in the system increased with increase in liquid flow rate and gas flow rate in the GCF regime. However, a steep rise in the pressure drop coincided with the onset of transition GCF to FP regime. The results are in accordance to the results reported by Weekman and Myers [6] and Wild et al. [7]. At high gas flow rates, transition from GCF to FP is observed at a low liquid flow rate.

The pressure drop for 4\% PEG solution was higher in comparison to 3\% PEG solution for both the GCF and FP regimes as shown in Figure 4. However as evident from Figure 4 that the pressure drop for foaming 3\% PEG and 4\% PEG was many folds in comparison with that of water 
Bulletin of Chemical Reaction Engineering \& Catalysis, 5 (1), 2010, 34

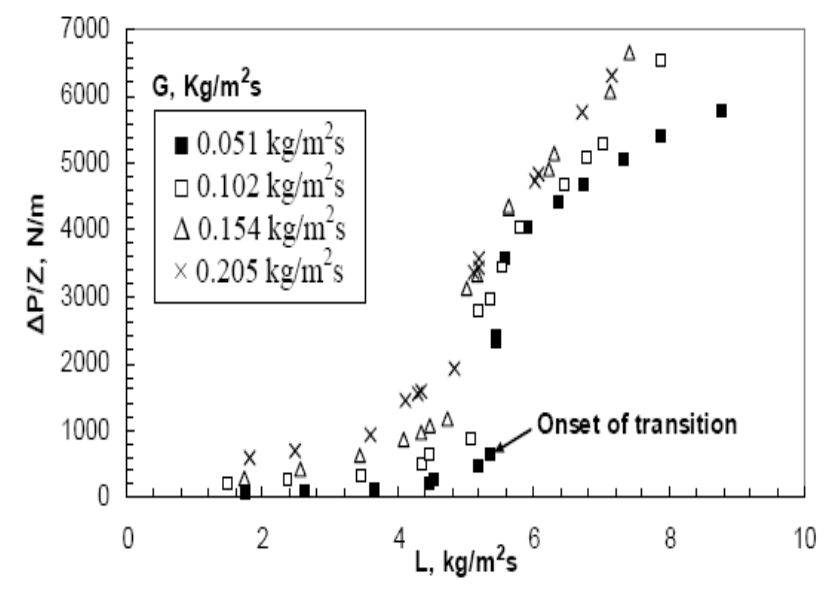

Figure 2. Plot of two-phase Pressure drop vs liquid flow rate for $3 \%$ aqueous PEG solution

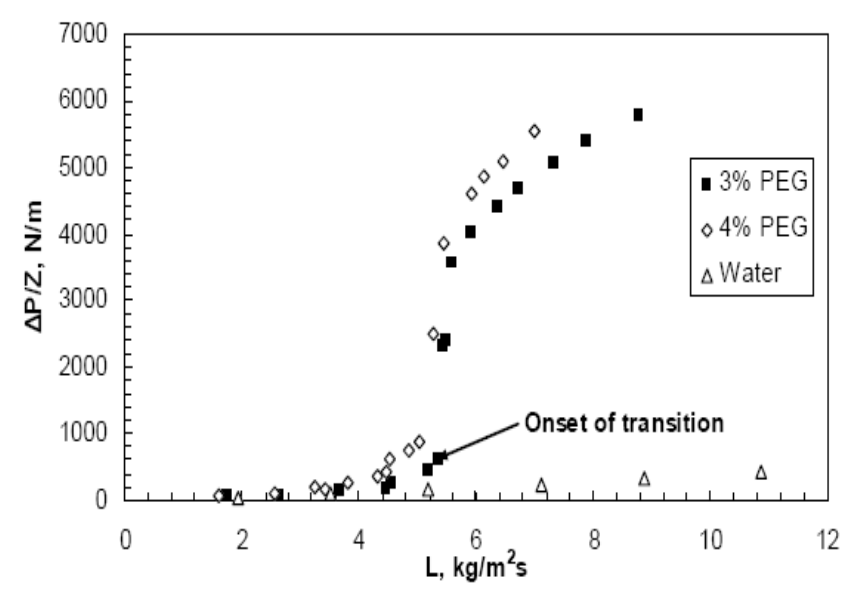

Figure 4. Two-phase Pressure drop for foaming and non foaming systems at $0.051 \mathrm{~kg} / \mathrm{m}^{2} \mathrm{~s}$ gas rate

(non-foaming) in FP regime.

\subsection{Dynamic Liquid Saturation}

Figures 5 and 6 show the plot of dynamic liquid saturation with liquid flow rate for $3 \%$ and $4 \%$ polyethylene glycol (PEG) at various gas flow rates.

\subsubsection{Effect of liquid flow rate}

It has been observed that in the GCF regime the dynamic liquid saturation increased with increase in liquid flow rate at the constant gas flow rate. As the flow rate is further increased, the foam was visually noticed in the column and corresponding to this flow rate, the transition from GCF to FP was observed. However, a dip in the dynamic liquid saturation was observed at the

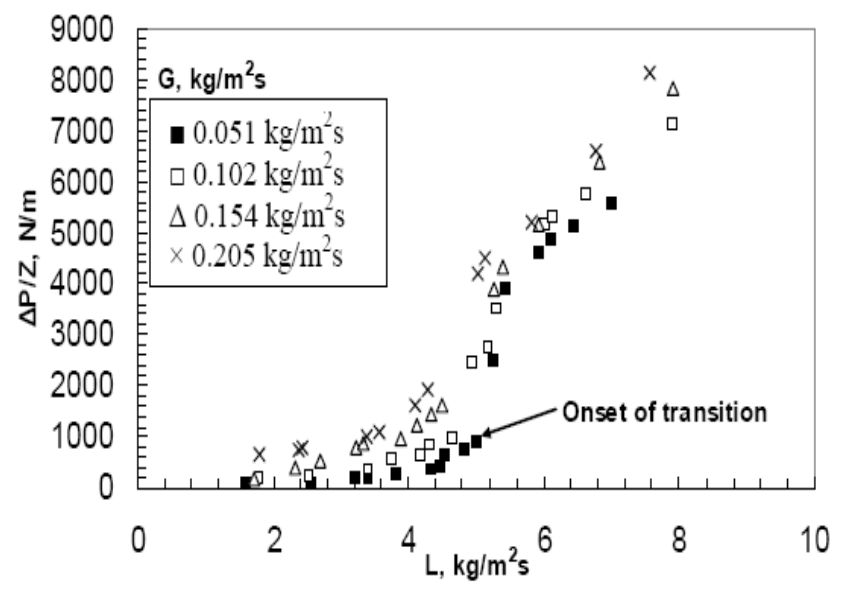

Figure 3. Plot of two-phase Pressure drop vs liquid flow rate for $4 \%$ aqueous PEG solution

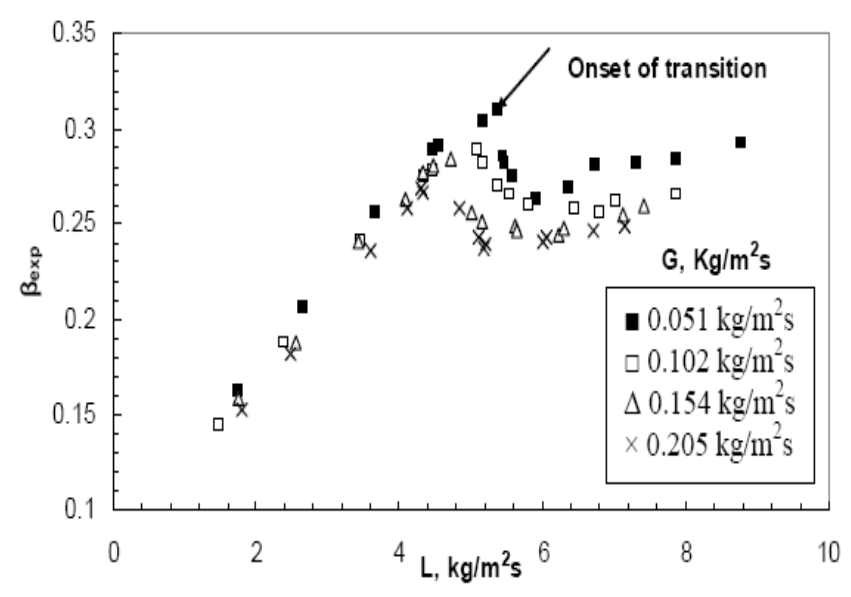

Figure 5. Dynamic liquid saturation vs liquid flow rate for $3 \%$ aqueous $\mathrm{PEG}$ solution

onset of the transition. The similar observations for decrease in dynamic liquid saturation and foaming characteristics at transition from GCF to FP have also been reported [8]. Further in the FP regime with increase in liquid flow rate the foaming intensity increased and hence the dynamic liquid saturation further deceased. With further increase in liquid flow rate the column was full of liquid foam and resulted in lowest dynamic liquid saturation. This may be due to the reason that during foaming large space was occupied by the gas phase which was otherwise occupied by the liquid. After the column is full of foam, further increase in liquid flow rate increased the dynamic liquid saturation. In the present study, dip in dynamic liquid saturation has been observed in the FP regime. 


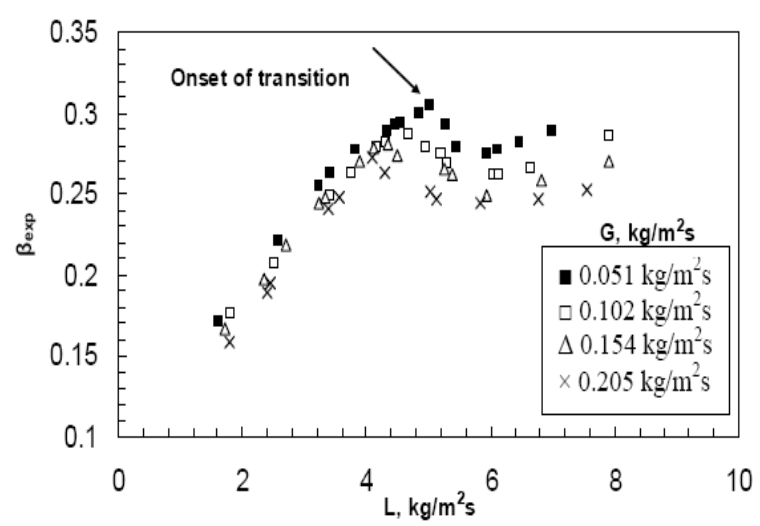

Figure 6. Dynamic liquid saturation vs liquid flow rate for $4 \%$ aqueous PEG solution

\subsubsection{Effect of Gas flow rate}

It is observed in Figures 5 and 6 that with increase in gas flow rate the dynamic liquid saturation decreased in GCF and FP regime. Also with increased gas flow rates the onset of transition from GCF to FP regime occurred at a lower liquid flow rate.

\subsubsection{Effect of viscosity}

Figure 7 shows the effect of viscosity on dynamic liquid saturation at $0.0512 \mathrm{~kg} / \mathrm{m}^{2} \mathrm{~s}$ gas flow rate for 3\% PEG and 4\% PEG. As the concentration of PEG increased from $3 \%$ to $4 \%$ in water, the viscosity of the fluid increased. It has been observed that dynamic liquid saturation for 4\% PEG is more than that for 3\% PEG at the same liquid and gas flow rate in the GCF regime. In the FP regime due to different foaming intensities the little variation in dynamic liquid saturation has been observed for 3\% and 4\% PEG. Further in the fully developed foam regime i.e after dip in dynamic liquid saturation, the dynamic liquid saturation for 4\% PEG is more compared to 3\% PEG. Also the onset of transition for 4\% PEG from GCF to PF is observed at a lower liquid flow rate compared to 3\% PEG for the given gas flow rate.

\subsubsection{Comparison of dynamic liquid saturation for foaming and non foaming fluids}

Figure 8 shows the parity for the dynamic liquid saturation for foaming $3 \%$ and $4 \%$ PEG aqueous liquids and non foaming water system. It has been observed that dynamic liquid saturation

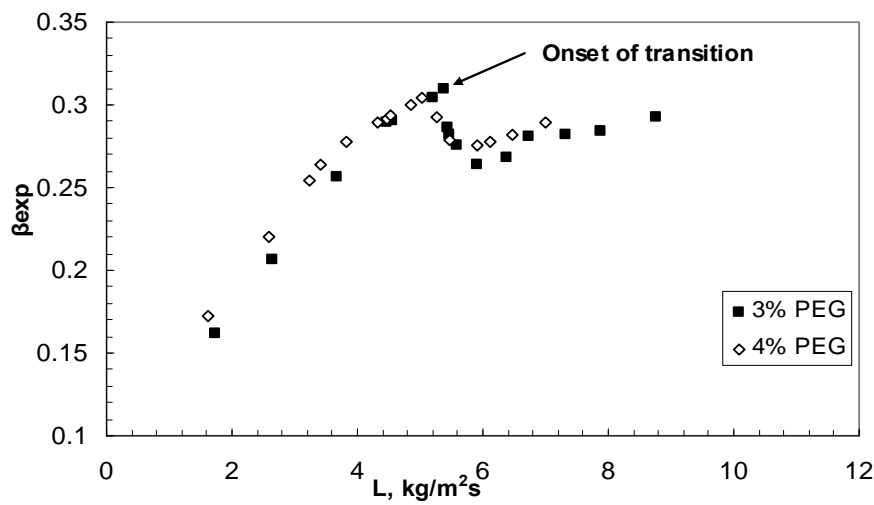

Figure 7. Comparison of dynamic liquid saturation for $3 \%$ and $4 \%$ aqueous PEG at $0.0512 \mathrm{~kg} / \mathrm{m}^{2} \mathrm{~s}$ gas flow rate

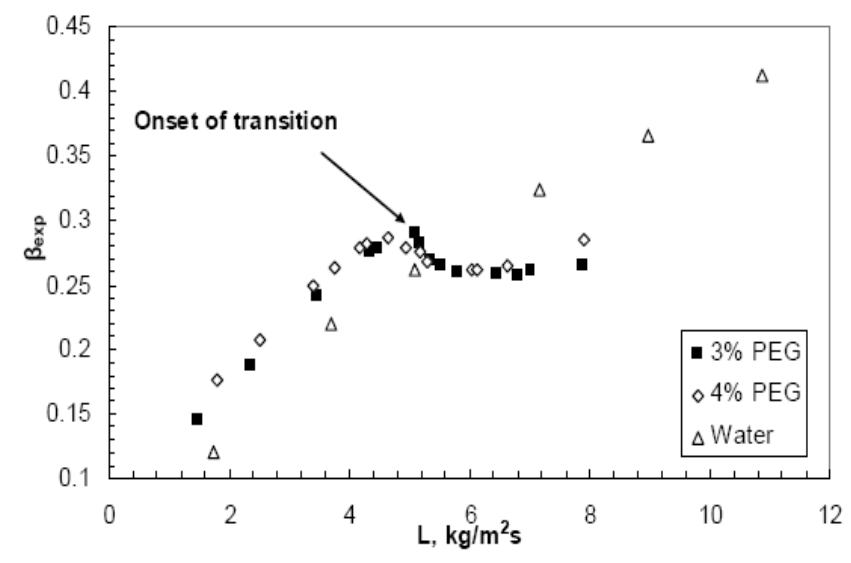

Figure 8. Comparison of dynamic liquid saturation for $3 \%$ PEG, $4 \%$ aqueous PEG and water at 0.102 $\mathrm{kg} / \mathrm{m}^{2} \mathrm{~s}$ gas flow rate

for water in GCF regime is lesser compared to that for 3\% and 4\% PEG solution at a given liquid and gas flow rate due to higher viscosity of $3 \%$ and $4 \%$ PEG solutions. The transition from GCF to $\mathrm{FP}$ is at lower liquid rate in case of $4 \% \mathrm{PEG}$ than for 3\% PEG and was at lower liquid rate for $3 \%$ PEG than for water.

\subsection{Transition from GCF to FP}

The visual observation of sharp rise in pressure drop and appearance of foam gives the indication of transition from GCF to FP regime. The liquid and gas flow rates for 3\% PEG and 4\% PEG at which transition from GCF to FP regime was observed are plotted on a log-log plot. The data obtained is compared with the reported correlation Bartelmus and Janecki [5] in Figure 9.

The data corresponding to non-foaming 


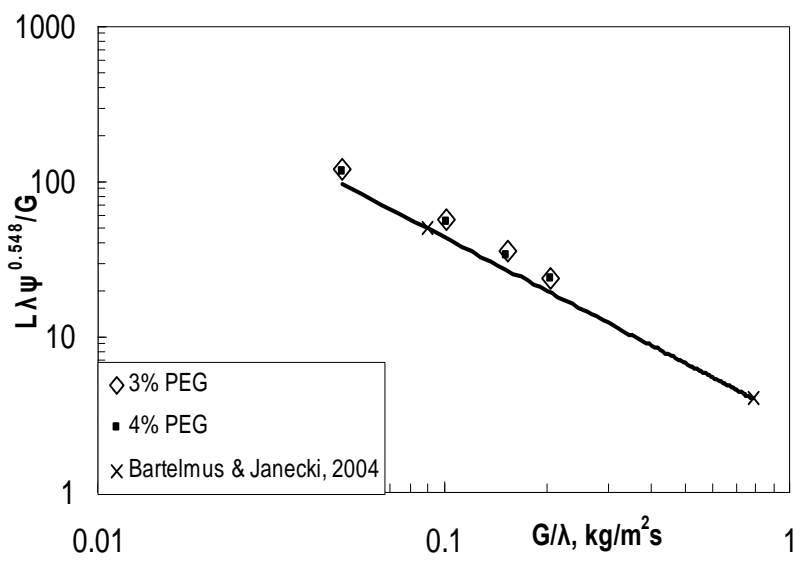

Figure 9. Comparison of regime transition data of the present work with literature correlation for foaming liquids

systems of Charpentier and Favier [2] and the present data corresponding to water is found to be in good agreement. Similarly for foaming systems data due to Chou et al. [3] and present data corresponding to $3 \%$ and $4 \%$ PEG aqueous solution is in good agreement. It is worth noting that the transition line for foaming system was lying below the corresponding line for non-foaming systems (Figure 10).

\section{Conclusion}

Based on the foregoing results and discussion the following major conclusions are drawn:

1. The pressure drop for foaming fluids is much higher compare to non-foaming fluids especially in FP regime.

2. For foaming liquids the transition from GCF to FP regime resulted into large foam that was visually seen. It leads to the sudden increase in the pressure drop in the column and a decrease in the dynamic liquid saturation collectively.

3. The dynamic liquid saturation decreased at the transition from GCF to FP regime due to the formation of foam which showed an increasing trend later resulting into a dip in the saturation curve.

4. At a higher gas flow rate the transition from GCF to FP occurred at low liquid rate.

5. The transition from GCF to FP occurred at low liquid flow rate for foaming liquids compared to that for the non-forming systems.

6. With increase in liquid viscosity both the dynamic liquid saturation and pressure drop increased.

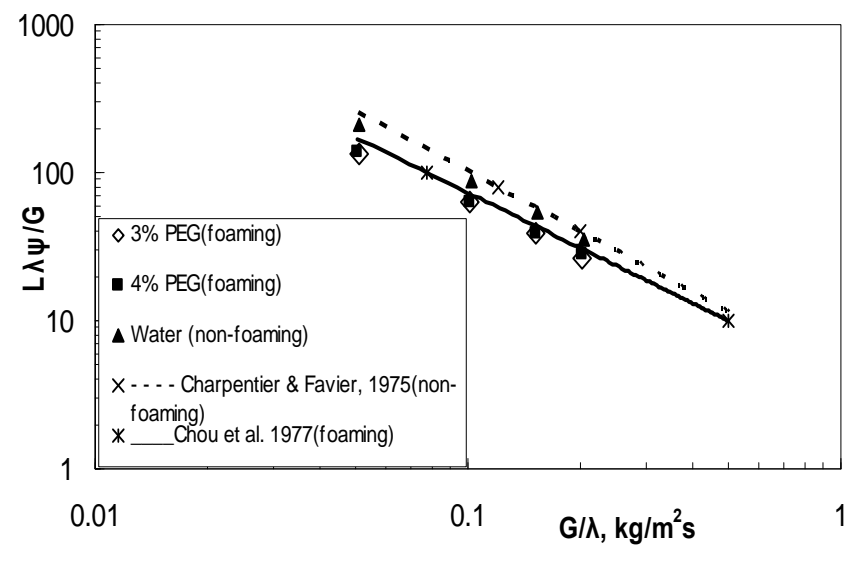

Figure 10. Comparison of regime transition data for foaming and non-foaming liquids of the present work with literature data

\section{Abbreviations and Acronyms}

G Gas mass velocity, $\mathrm{kg} / \mathrm{m}^{2} \mathrm{~s}$

$\mathrm{L} \quad$ Liquid mass velocity, $\mathrm{kg} / \mathrm{m}^{2} \mathrm{~s}$

$\Delta \mathrm{P} \quad$ Two-phase pressure drop, $\mathrm{N} / \mathrm{m}^{2}$

Z Packed bed height, $m$

$\rho_{g} \quad$ Density of Gas, $\mathrm{kg} / \mathrm{m}^{3}$

$\rho_{\text {Air }} \quad$ Density of Air, $\mathrm{kg} / \mathrm{m}^{3}$

$\rho_{\mathrm{L}} \quad$ Density of Liquid, $\mathrm{kg} / \mathrm{m}^{3}$

$\rho_{\mathrm{w}} \quad$ Density of Water, $\mathrm{kg} / \mathrm{m}^{3}$

$\sigma_{\mathrm{w}} \quad$ Surface tension of water, $\mathrm{N} / \mathrm{m}$

$\sigma_{\mathrm{L}} \quad$ Surface tension of water, $\mathrm{N} / \mathrm{m}$

$\mu_{\mathrm{L}} \quad$ Viscosity of Liquid, $\mathrm{kg} / \mathrm{m}$.s

$\mu_{\mathrm{w}} \quad$ Viscosity of water, $\mathrm{kg} / \mathrm{m} . \mathrm{s}$

Bexp Dynamic liquid saturation, experimental value

$\lambda$

$$
\left(\frac{\rho_{g}}{\rho_{\text {Air }}} \cdot \frac{\rho_{L}}{\rho_{w}}\right)^{0.5}
$$

$$
\left(\frac{\sigma_{w}}{\sigma_{L}}\right)\left[\frac{\mu_{L}}{\mu_{w}} \cdot\left(\frac{\rho_{w}}{\rho_{L}}\right)^{2}\right]^{1 / 3}
$$




\section{REFERENCES}

[1] Iliuta, I.; Larachi, F. 2009. Trickle bed mechanistic model for non-Newtonian power-law foaming liquids. Chemical Engineering Science. 64: 1654-1664.

[2] Charpentier, J. C.; and Favier, M. 1975. Some liquid holdup experimental data in trickle-bed reactors for foaming and non-foaming hydrocarbons. American Institute of Chemical Engineering Journal 21: 1213-1218.

[3] Chou, T. S.; Worley, F. L.; Luss D. 1977. Transition to pulsed flow in mixed phase cocurrent downflow through a fixed bed. Industrial Engineering Chemical Process Design Development 16: 424-427.

[4] Midoux, N.; Favier, M.; Charpentier, J.C. 1976. Flow pattern, pressure loss and liquid holdup data in gas-liquid downflow packed beds with foaming and non-foaming hydrocarbons, $J$. Chemical Engineering Japan 9: 350-356.

[5] Bartelmus, G.; Janecki, D. 2004. Hydrodynamics of the co-current downflow of a gas and a foaming liquid through a packed bed. Part I. Estimation of the transition boundary between the hydrodynamic regimes from the gas continuous flow to the pulsing flow. Chemical Engineering Process 43: 169-179.

[6] Weekman, V. W.; Myers, J. E. 1964. Fluid-flow characteristics of co current gas-liquid flow in packed beds. American Institute of Chemical Engineering Journal 10: 951-957.
[7] Wild, G.; Larachi, F.; Laurent, A. 1991. The hydrodynamic characteristics of cocurrent downflow and cocurrent upflow gas-liquid-solid catalytic fixed-bed reactors: The effect of pressure. Rev. Inst.Franç. Pétr. 46: 467-490.

[8] Bartelmus, G.; Janecki, D. 2003. Hydrodynamics of a co-current downflow of gas and foaming liquid through the packed bed. Part II. Liquid holdup and gas pressure drop. Chemical Engineering Process 42: 993-1005.

[9] Janecki, D.; Bartelmus, G.; Krotki, T. 2005. The hydrodynamics of the pressure trickle bed reactor with packed bed for foaming system, in Proceedings of the Seventh World Congress Chemical Engineering, Glasgow, United Kingdom.

[10] Aydin, B.; Larachi, F. 2008. Trickle bed hydrodynamics for non-Newtonian foaming liquids in non-ambient conditions. Chemical Engineering Journal 143: 236-243.

[11] Bansal, A.; Wanchoo, R. K.; Sharma S. K. 2008. Two-Phase Pressure Drop in a Trickle Bed Reactor Involving Newtonian/Non-Newtonian Liquid Phase. Chemical Engineering Communication 195: 1106-1127.

[12] Bansal, A.; Wanchoo, R. K.; Sharma, S. K. 2009. Dynamic Liquid Saturation in a Trickle Bed Reactor involving Newtonian /non-Newtonian Liquid-Phase. Industrial Engineering Chemistry Research 48: 3341-3350. 